\title{
A articulação entre turismo, vinho e a gastronomia na região da Campanha Gaúcha, Brasil
}

The articulation between tourism, wine and gastronomy in the region of Campaign Gaúcha, Brazil

\section{Vanessa Manfio}

Instituto Federal do Rio Grande do Sul - IFRS - Porto Alegre - Rio Grande do Sul - Brasil

Resumo: O vinho é mais que uma bebida. É uma fonte de lembranças e de cultura, assim como é responsável pela articulação territorial e econômica de muitas regiões reconhecidas mundialmente. A partir da dinâmica vitícola cria-se outras atividades, como o turismo. O turismo do vinho vem, em muitos casos articulados ao turismo gastronômico regional. Como acontece na Campanha Gaúcha, localizada no sudoeste do Rio Grande do Sul, onde a enogastronomia está se desenvolvendo através de festivais, de rotas turísticas, entre outras atrações, promovidas pelos atores locais. Nesta região, o vinho articula-se com a culinária gaúcha. Diante disso, este artigo busca analisar o desenvolvimento do turismo na Campanha Gaúcha, avaliando as relações entre vinho e gastronomia, a partir da abordagem qualitativa e dos recursos metodológicos, tais quais: revisão de literatura, entrevistas semiestruturas, conversas informais, análise da paisagem e coleta de dados. Esperando, com este trabalho, contribuir para as discussões a respeito da enogastronomia no âmbito da Campanha Gaúcha.

Palavras-chave: Enoturismo. Gastronomia. Campanha Gaúcha.

\begin{abstract}
Wine is more than a drink. It is a source of memories and culture, as well as responsible for the territorial and economic articulation of many regions recognized worldwide. From the dynamics of winemaking, other activities are created, such as tourism. Wine tourism comes in many cases linked to regional gastronomic tourism. As it happens in the Campaign Gaúcha, located in the southwest of Rio Grande do Sul, where enogastronomy is developing through festivals, tourist routes, among other attractions, promoted by local actors. In this region, the wine joins with the gaucho cuisine. This article aims to analyze the development of tourism in the Campaign Gaúcha, evaluating the relations between wine and gastronomy, from the qualitative approach and the methodological resources, such as: literature review, semi-structured interviews, informal conversations, landscape analysis and data collect. Hoping, with this work, to contribute to the discussions about the enogastronomy in the ambit of the Campaign Gaúcha.
\end{abstract}

Keywords: Wine tourism. Gastronomy. Campaign Gaúcha. 


\section{Introdução:}

A vitivinicultura tem sido uma atividade em crescente expansão territorial no Brasil. Esta vem agregando diferentes olhares sobre o cultural, o fazer o vinho, o espaço das regiões vitícolas e a gastronomia regional.

Nestas regiões também o enoturismo está se desenvolvendo, trazendo novas "roupagens" para as cidades e espaços rurais. O enoturismo é o segmento turístico que envolve a visitação à cultura e aos detalhes do vinho (VALDUGA, 2011).

É evidente também a associação entre vinho e alimentação. Esta associação não é recente, sendo citada já na Bíblia, nas passagens da última ceia de Jesus. No entanto, os atores que articulam o turismo, principalmente em regiões produtoras de vinhos, estão cada vez mais incrementando atividade que envolve estes dois elementos, criando um novo conceito de turismo, a enogastronomia.

Diante disso, este trabalho busca discutir a respeito da associação entre culinária e vinho no desenvolvimento do turismo na Campanha Gaúcha, região sudoeste do Rio Grande do Sul, Brasil. Esperase com o trabalho contribuir para os estudos ligados à vitivinicultura e turismo desta região, tecendo novas discussões para futuros estudos na área.

Este trabalho foi construído a partir dos estudos e informações coletas durante, 2014-2018, para a tese apresentada na Universidade Federal do Rio Grande do Sul. Na pesquisa foi utilizada a abordagem qualitativa e os recursos metodológicos, entrevistas semiestruturadas, coleta de dados, registro de informações e revisão de literatura.

O presente artigo articula-se em três etapas: primeiro a discussão sobre o enoturismo e a gastronomia, em segundo a abordagem do enoturismo e a associação com a culinária local na Campanha Gaúcha, fechando com as considerações do trabalho.

\section{0 turismo e a gastronomia nos ambientes vitícolas: uma discussão teórica}

O enoturismo faz referência a um tipo de turismo que envolve o vinho, o ambiente local e a cultura. De acordo com Brambilla (2015, p.43):
O termo enoturismo é a junção do prefixo grego eno (vinho) com a palavra turismo. $\mathrm{O}$ enoturismo ou turismo de vinhos pode ser caracterizado pelo deslocamento de pessoas para destinos que exploram a vitivinicultura tendo, portanto, tradição na produção de uvas e fabricação de vinhos. Nada impedindo que regiões emergentes, que lidem com este setor, possam desenvolver este segmento turístico.

Completando este autor, Hall et all.(2004) coloca que o enoturismo pode ser entendido como um conjunto de atividades que envolvem: visitação de vinhas, vinícolas, festivais do vinho ou ainda mostras de uvas em que a fonte de motivação dos visitantes refere-se à degustação de vinhos e aos atributos de uma região vitivinícola pode oferecer, como: gastronomia, história e atrativos locais.

Na visão de Zanini (2007), o enoturismo pode ser considerado turismo rural e cultural, com diversos campos de exploração, como: a natureza onde se encontram os vinhedos, a cultura das famílias, sua gastronomia, a história dos patrimônios locais, entre outros.

Logo, "O vinho, assim, é o protagonista da dinâmica do enoturismo" (BRAMBILLA (2015, p.43). Para Santos (2004, p. 7), “o vinho não é apenas uma bebida, mas uma viagem pela história, geografia, cultura e economia de cada região".

Mas, o vinho não tem apenas uma dimensão econômica e concreta (visível). Conforme Pivot (2007), ele apresenta também uma dimensão cultural, que abrange a cultura da vinha e o espírito, já que o mesmo é referência de mitologias e da memória de muitas pessoas, evocando sentimentos. Esta memória também evoca ao enoturismo.

Além disso, "o enoturismo pode ser motivado ainda pela particularidade da paisagem dos vinhedos ou pela busca de lazer, não estando estes diretamente associados ao consumo do vinho" (CHIATTONE; CHIATTONE, 2013, p. 623).

Dessa forma, a pessoa que se dirige até as regiões vinícolas é compreendida como "o sujeito que, a partir de seu desejo de fuga do cotidiano, de nomadismo, de desligamento, deslocou-se de seu local de residência e deseja conhecer algum aspecto relacionado à vitivinicultura" (VALDUGA, 2012, p.130). 
Para Chiattone e Chiattone (2013, p.618),

\begin{abstract}
O enoturismo, considerado um segmento do turismo gastronômico e também conhecido como turismo do vinho, tem se destacado dentre as novas modalidades turísticas consolidadas nas últimas décadas. No entanto, existem poucos estudos sistemáticos sobre seu desenvolvimento, sua gestão e planejamento e sobre os turistas que experimentam o produto enoturístico.
\end{abstract}

Logo, o enoturismo e a gastronomia estão intimamente ligados. Pois, um vinho sempre é acompanhado por uma boa comida. Assim, vinho e alimentação são dois elementos que se articulam entre si. De acordo com Donald Getz, 2000; Szivas, 1999 apud Oliveira (2010, p.52), "O vinho e a gastronomia, para muitos, são elementos inseparáveis, e em termos de turismo, a ligação entre ambos tem vindo a ser cada vez mais reforçada".

Conforme Valduga (2007), como o beber está associado ao comer, o enoturismo deu espaço também para o crescimento da enogastronomia, agregando o vinho e ao ambiente.

Ainda, a gastronomia é um elo com o espaço regional. Conforme Pertile e Gastal (2011, p. 5), "A gastronomia de uma determinada região é tida como patrimônio cultural intangível, já que além de seus ingredientes ela necessita de um "saber-fazer"'.

Ressalta, neste sentido, Chiattone e Chiattone (2013, p. 617) que,

\begin{abstract}
Através da culinária típica local, as pessoas podem conhecer os povos, suas tradições, história e costumes, de uma forma muito saborosa. $O$ valor cultural do ato gastronômico associado com a história dispõe ao visitante um exemplo da raiz e da evolução da identidade cultural da localidade visitada.
\end{abstract}

Nesta discussão, Zago (2009) diz que, "O turismo enogastronômico contribui para valorizar o patrimônio, por um lado, atraindo um número sempre crescente de apaixonados pela procura de sabores e de tradições autênticas e, por outro lado, fazendo do alimento um condutor de culturas e de valores firmemente ligado ao território e às próprias raízes (ZAGO, 2009, p.2, apud PERTILE; GASTAL, 2011, p. 7).
Conforme Schlüter (2003), o turismo gastronômico e o enoturismo valorizam a tradição e preservação do patrimônio histórico e cultural, além de possuir forte ligação com o meio rural. Isto significa que o enoturismo precisa valorizar a identidade regional, pois a criação de algumas atividades (como, spa do vinho na Serra Gaúcha), podem implicar numa ruptura com o patrimônio, tornando-se uma desmotivação para os anseios do turista.

Portanto, os dois tipos de turismo se complementam e são utilizados pelas vinícolas que além de passeios, promovem degustações de vinhos com pratos da culinária típica do regional. Em Lavandoski e Tonini (2010, p. 7),

"Para melhor desenvolver a atividade enoturística e adequar a oferta aos desejos e interesses do visitante, os empreendimentos vitivinícolas criam rotas com atrativos definidos - visitação, degustação, pratos típicos, contato com moradores e cultura local, entre outros transformando a região em si em um produto turístico".

Esta prática acontece no Vale dos Vinhedos, onde o vinho e a culinária italiana são elementos impulsionadores do turismo e se completam, pois o turista que viaja para esta região quer conhecer também a tradição italiana.

A região da Campanha Gaúcha, nova produtora de vinhos, também tem investido nesta filosofia de criar atividades turísticas e roteiros que envolvam a culinária gaúcha e o vinho.

Esta condição enogastronômica tem sido impulsionadora do turismo as regiões vitícolas e de desenvolvimento das regiões, articulando diferentes atores locais e setores econômicos.

\section{O Enoturismo e a culinária gaúcha: apontamentos sobre a Campanha Gaúcha}

O avanço da vitivinicultura dentro do espaço do Rio Grande do Sul levou ao surgimento de uma nova região vitícola, a Campanha Gaúcha, localizada na Fronteira Sudoeste do estado (Figura 1). 
Figura 1 - Mapa de localização da região vitícola da Campanha Gaúcha

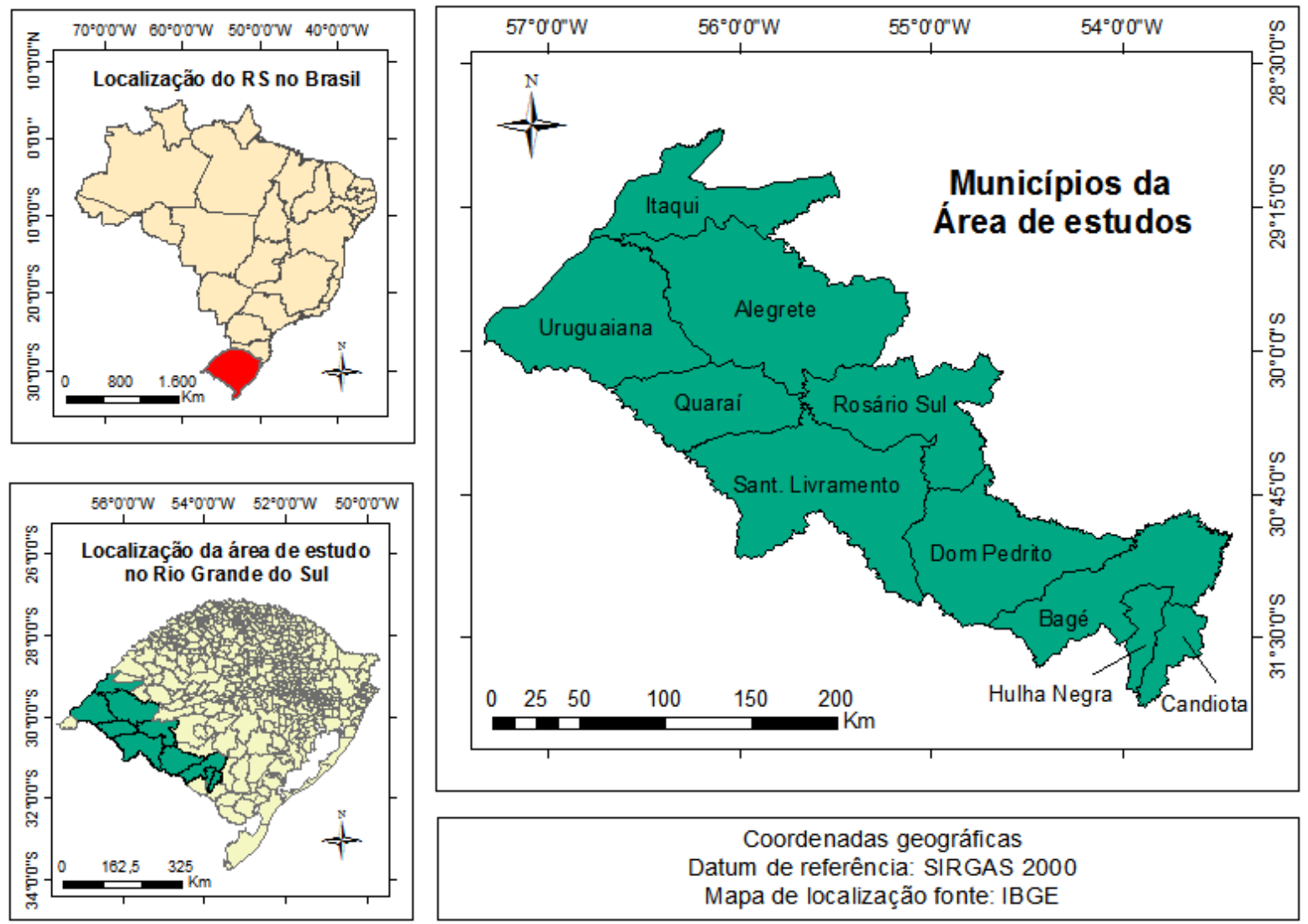

Org.: SBRUZZI, J. B.; MANFIO, V. (2015).

Esta região iniciou a produção de uvas a partir da década de 1970, quando estudos edafoclimáticos sinalizaram condições propícias para produção de uva (FLORES, 2011). Depois disso, empresas se instalaram na região e empreendedores locais investiram na vitivinicultura transformando o espaço e a paisagem. Estes produtores de uva e vinho no intuito de promover a gestão da região vitícola criaram a Associação dos Produtores de Vinhos Finos da Campanha Gaúcha (Associação Vinhos da Campanha).

Retomando a respeito das características da região, esta é marcada pela pecuária e agricultura e apresenta uma forte história ligada à constituição do RS - especialmente da Revolução Farroupilha. Estas características deixam marca na região.

A cultura gaúcha também é uma marca regional, sendo visualizada nos hábitos dos moradores locais através do chimarrão, do andar a cavalo, da vestimenta do gaúcho, da lida campeira, da culinária e arquitetura, entre outras formas.

Logo, a vitivinicultura que se desenvolve na Campanha Gaúcha tem buscado construir uma identidade que se articula o vinho com a cultura gaúcha e o patrimônio histórico e ambiental da região. Esta associação é utilizada também no desenvolvimento do enoturismo, que ora vem sendo organizado pelos atores vitícolas e pela Associação Vinhos da Campanha.

Conforme Flores (2015, p. 60):

Na Campanha Gaúcha é possível observar o vínculo dos vinhos com o "gaúcho" e elementos da cultura local, tais como o bioma pampa, pecuária (ovina e bovina), cavalos, o vento "minuano", o relevo do pampa e os cerros. Tais elementos aparecem na fotografia, iconografia, elementos de linguagem das vinícolas e discurso dos atores. No material de comunicação das vinícolas, elementos históricos ou relacionados ao bioma pampa aparecem no nome dos vinhos e rótulos. O 
apelo histórico se dá colocando em evidência o gaúcho e fatos locais, como a Revolução Farroupilha.

Assim, com a criação de uma identidade para o território vitícola da Campanha Gaúcha é possível apresentar singularidade ao vinho e ao enoturismo da região (MANFIO, 2018). Esta identificação dos produtos vitícolas com a região também fortalece o turismo regional (FLORES, 2011).

No que tange o enoturismo na região, este "originou-se por iniciativas pontuais, que valorizavam os elementos vitícolas e o contexto regional identitário. Pontuais, porque as cidades da Campanha são distantes umas das outras e a vitivinicultura é uma atividade recente" (MANFIO, 2018, p. 191). Completa ainda a mesma autora que atualmente, estão ocorrendo além de práticas pontuais, a articulação entre empresas vitícolas, criando rotas e eventos enoturísticos, que envolvem visitação, participação em vindima, eventos gastronômicos e a degustação de vinho e da culinária gaúcha. A degustação acontece, principalmente através de almoços harmonizados (figura 2), promovidos pelas vinícolas.

Sobre os almoços, Manfio (2018, p. 191) menciona ainda que "Nos almoços são degustados os vinhos e servido pratos típicos da gastronomia local como parrilla de cordeiro, entrecort de carne de gado, churrasco de chão, arroz carreteiro de charque, creme de moranga e especiarias".

Figura 2 - Almoço harmonizado da Vinícola Guatambu

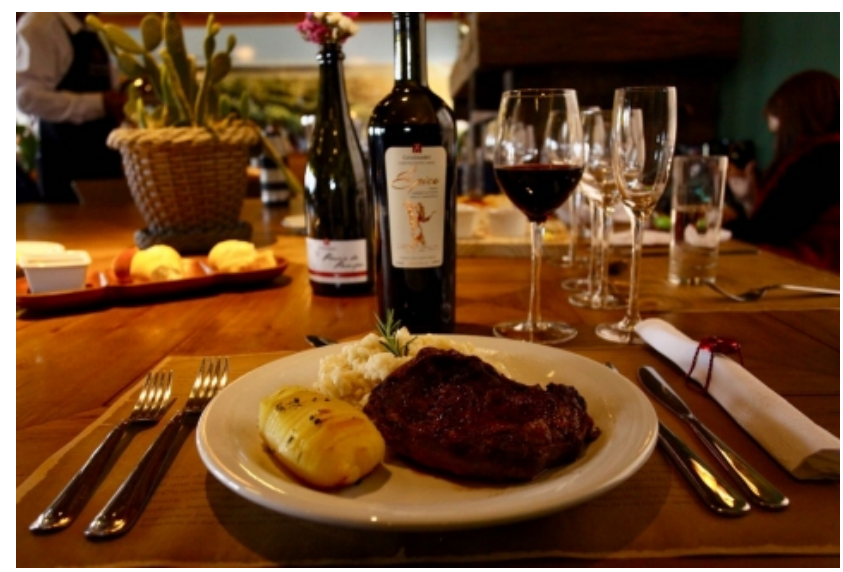

Fonte:

disponível

em:

http://www.guatambuvinhos.com.br/album.php?ida=7 \#divMenuUtil
Além dos almoços, existem eventos na Campanha Gaúcha que estão unindo a gastronomia e o vinho. Um destes eventos é o Festival Binacional de Enogastronomia e Produtos do Pampa que acontece em Santana do Livramento. Este evento reúne restaurantes e vinícolas das cidades de: Rivera (Uruguai) e da Campanha Gaúcha (Brasil). O Festival envolve: a) palestras e oficinas; b) passeio à Ferradura dos Vinhedos e às vinícolas uruguaias, entre elas a Bodega Carrau; c) jantares com pratos típicos e degustação de vinhos (FESTIVAL BINACIONAL DE ENOGASTRONOMIA, 2016).

Em 2018, ocorreu a $5^{a}$ edição e reuniu também amostra de artesanato e exposição fotográfica da fronteira gaúcha. Sem dúvidas, é um evento de promoção da região vitícola da Campanha Gaúcha, permitindo o desenvolvimento do turismo local e de outras atividades ligadas ao setor.

A Rota Turística da Ferradura dos Vinhedos (Figura 3), em Santana do Livramento, também é uma iniciativa de promoção para a enogastronomia e turismo regional. Essa rota, com um formato de ferradura, foi oficializada em 2018, mas desde 2010, o professor Avelar Fortunato da UNIPAMPA de Santana do Livramento, vinha trabalhando na implementação da mesma (BUENO, 2018).

Figura 3 - Rota Turística da Ferradura dos Vinhedos

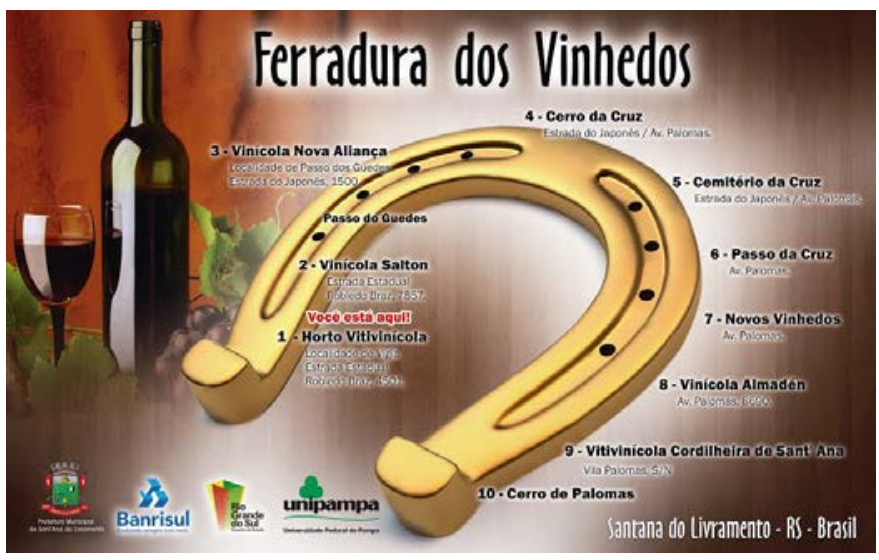

Fonte: UNIPAMPA, 2014

Disponível

em: http://www.unipampa.edu.br/portal/noticias/38182014-12-26-18-06-14.

Ademais, a Ferradura dos Vinhedos consiste numa nova iniciativa de articulação entre vinícolas, poder público local e outros segmentos econômicos. 
Sobre as atividades da rota, Manfio, Pierozan e Medeiros (2016, p. 11) comentam que,

Os passeios turísticos do Projeto Ferradura dos Vinhedos possuem acompanhamento de guias turísticos, e são realizados aos domingos (de quinze em quinze dias). Contemplam a visitação das vinícolas do município de Santana do Livramento (Vinícola Almadén, Cordilheira Santana, Salton e Nova Aliança), e os lugares históricos e naturais, terminando com almoço no Centro de Tradições Gaúchas: Presilha do Pago.

A Rota Pampa Gaúcho também está se desenvolvendo, a fim de alavancar o turismo na região. Esta rota envolve passeio pelas vinícolas de Candiota, Bagé, Dom Pedrito e Santana do Livramento, visitas a espaços histório-culturais (como o Museu Dom Diogo em Bagé e a cidade cenográfica de Santa Fé) e hospedagens com refeições na Pousada do Sobrado e Hotel Alexandre, além de outros estabelecimentos gastronômicos.

Outras atividades vêm acontecendo na região da Campanha Gaúcha que estão movimentando a enograstronomia. Muitos hotéis e pousadas estão criando passeios de visitação às vinícolas e oferecendo cafés e almoços com a culinária regional.

Convém destacar que a região está se articulando aos poucos para implantar um turismo enogastronômico. Ainda, existem muitas dificuldades a serem superadas, principalmente em infraestrutura e parceria entre empreendimentos regionais. Porém, aos poucos vão se implantando roteiros e rotas para driblar estes obstáculos ao enoturismo.

Em suma, a região vem valorizando os elementos regionais no desenvolvimento a enogastronomia, como uma forma de manter um desenvolvimento sustentável e constituinte de um patrimônio, que se difere das demais regiões vitícolas do país e do mundo.

\section{Considerações}

A expansão da vitivinicultura brasileira, principalmente em área de produção, tem permitido também 0 desenvolvimento de atividades enoturísticas. Estas atividades estão, cada vez mais, articulando a paisagem e a gastronomia, reforçando as identidades regionais e permitindo a singularidade turística

Assim, atualmente fala-se muito em enogastronomia, que condiz a um novo conceito que envolve vinho, gastronomia e turismo. Conceito muito utilizado no Vale dos Vinhedos no Rio Grande do Sul.

Na Campanha Gaúcha, por sua vez, o turismo vem se completando unindo a culinária e tradição gaúcha mais o vinho. Além de envolver lugares históricos e ambientais. É uma nova região com potencial para produção de vinhos e turismo.

Nesta região de fronteira do Rio Grande do Sul, o turismo encontra-se em implantação surgindo algumas rotas e eventos enogastronômicas, tais quais: a rota Ferradura dos Vinhedos e o Festival Binacional de Enogastronomia e Produtos do Pampa, importantes para a enogastronomia, que ora se desenvolve na região. Estas iniciativas turísticas demonstram a parceria dos atores locais para enfrentar as dificuldades regionais, trazendo possibilidades de desenvolvimento regional.

Além disso, cultura gaúcha é a identidade expressiva na região. Dessa forma, o turismo na região busca articular vinho, cultura gaúcha e paisagem. Dentro da cultura, está a gastronomia. Assim, produz peculiaridade para região.

Diferentemente que na Serra Gaúcha, onde a culinária italiana e o vinho são elementos essenciais do turismo. Na Campanha Gaúcha é a culinária gaúcha, principalmente o churrasco e o arroz carreteiro estão regados de vinhos regionais.

Ao superar as dificuldades da Campanha Gaúcha, a região tende a se tornar importante neste segmento do turismo - o enogastronômico. Com isto, o desenvolvimento regional será reforçado com a criação de infraestrutura, movimento de pessoas que trazem a geração de emprego e renda e a própria visibilidade à região. Em suma, o vinho e a gastronomia, são o ponto - chave para promoção regional e o desenvolvimento turístico. 


\section{Referências}

1 BRAMBILLA, A. Cultura e enoturismo: um estudo na Região Demarcada do Douro. 2015. Aveiro. Universidade de Aveiro, 2015.

2 BUENO, E. T. Projeto Ferradura dos Vinhedos da Unipampa é oficializado como atrativo turístico do Rio Grande do Sul. 2018. Disponível em: http://novoportal.unipampa.edu.br/novoportal/proj eto-ferradura-dos-vinhedos-da-unipampa-eoficializado-como-atrativo-turistico-do-rio-grandedo. Acesso em: 10 de jan. De 2019.

3 ChiAtTONE, M. V.; ChiatTONE, P. V. Enoturismo: Atrativo e Ferramenta para o Desenvolvimento Sustentável de Regiões. Revista Rosa dos Ventos, Caxias do Sul. 5(4) 616-634, out-dez, 2013.

4 FESTIVAL BINACIONAL DE ENOGASTRONOMIA. Sobre o evento. Disponível em: https://www.festivalbinacionalenogastronomia.co m/. Acesso em: 12 de dez. de 2018.

5 FLORES, S. S. Desenvolvimento territorial sustentável a partir dos territórios do vinho: 0 caso dos "Vinhos da Campanha." 2011. $153 f$. Dissertação (Mestrado em Geografia) Universidade Federal do Rio Grande do Sul, Porto Alegre, 2011. Vinho e identidade no Brasil: da Itália ao vinho tipicamente brasileiro. In: ENCONTRO NACIONAL DE GRUPOS DE PESQUISA, VIII., 2015. Florianópolis. Anais ... Florianópolis: UFSC, 2015b. p. 60-61.

7 HALL, M. et al. Wine Tourism: an introduction. In: HALL, M. et al.(Org.). Wine tourism around the world. 3. ed. Estados Unidos: BetterworthHeinemann, 2004.

8 LAVANDOSKI, J.; TONINI, H. Enoturismo: experiências e sensações no Vale dos Vinhedos (RS). In: SEMINÁRIO DE PESQUISA EM TURISMO DO MERCOSUL, IV.,2010. Caxias do Sul. Anais... Caxias do Sul: UCS, 9 a 10 de 2010.

9 LOCKS, E. B. D.; TONINI, H. Enoturismo: O vinho como produto turístico.Turismo em Análise, v, 16, n, 2, p. 157-173, novembro 2005.

10 MANFIO, V.; PIEROZAN, V. L.MEDEIROS, R. M. V. Enoturismo e desenvolvimento rural: dinâmicas e perspectivas do Vale dos Vinhedos e da Campanha Gaúcha - RS. In: ENCONTRO NACIONAL DE GEOGRAFIA AGRÁRIA, XXIII., 2016. São Cristóvão-SE. Anais... São CristóvãoSE: UFS, 9 a 13 de nov. De 2016.

11 MANFIO, V. Vitivinicultura e associativismo: a dinâmica da Associação Vinhos da Campanha na formação de um território no Rio Grande do Sul, Brasil. 260f. 2018. Tese (Doutorado em

Geografia) - Universidade Federal do Rio Grande do Sul. Porto Alegre, 2018.

OLIVEIRA, S. P. R. de. A gastronomia e o vinho como factores potenciadores de turismo. $100 f$. 2010. Doutorado (doutorado em Administração de empresas e comércio internacional) Universidade de Extremadura, Badajoz - EP, 2010.

PERTILE, K.; GASTAL, S. de A. Enoturismo e gastronomia: (re) pensando o Vale dos Vinhedos - RS. In: ENCONTRO SEMINTUR JR, II., Caxias do Sul. Anais... Caxias do Sul: UCS, 2011.

14 PIVOT, B. Dicionário Sentimental do Vinho. Alfragide: Casa das Letras, 2007.

SANTOS, J. I. Vinhos, o essencial. São Paulo: Senac, 2004.

SCHLÜTER, R. Gastronomia e turismo. Tradução de Roberto Sperling. São Paulo: Aleph, 2003.

17 VALDUGA, V. O processo de desenvolvimento do enoturismo no Vale dos Vinhedos. 151f. 2007. Dissertação (Mestrado em Turismo)Universidade de Caxias do Sul, Caxias do Sul, 2007.

Enoturismo no vale dos Vinhedos. Jaguarão: Fundação da Universidade Federal do Pampa, 2011.

O desenvolvimento do enoturismo no Vale dos Vinhedos (RS/Brasil). Cultur, v.6, n.2, pp. 127-143, 2012.

20 ZANINI, V.T. Enoturismo no Brasil: um estudo comparativo entre as regiões vinícolas do Vale dos Vinhedos (RS) e do vale do São Francisco (BA/PE). Caxias do Sul, 2007. 